\title{
Demand Analysis of Termite Control Service in Jakarta
}

\author{
By: \\ Mohamad Miftah Rahman ${ }^{1}$, Dodi Nandika ${ }^{1}$, Bintang Charles Hamonangan \\ Simangunsong ${ }^{*}$ \\ ${ }^{1}$ Department of Forest Products, Faculty of Forestry, IPB University. Jl. Ulin Lingkar Akademik Kampus IPB \\ Darmaga, Bogor, 16680, West Java, Indonesia \\ *email: bintangcsimangunsong@gmail.com
}

\begin{abstract}
Termite is an economically important pest species in the pest control industry and considered as one of the urban pests. Although it had caused a great loss, only a few studies on termite control demand were found. This study attempted to identify determinants and build the econometric model of termite control demand in Jakarta. The findings are expected to give the pest control industry a better understanding of the pest control market. Two ad-hoc models, linear and double log models, were investigated using the Least Square Dummy Variable (LSDV) technique. The results showed that the double log model was found better than the linear model based on sign expectation and significance. The price of termite control service, building permits, price of structural metals and dummy variables for the large company were statistically significant determinants, whereas dummy variables for risk class were not. Termite control demand for medium and small companies was not significantly different, but both of them were significantly lower than demand for the large company. This study also found that the demand for termite control was elastic.
\end{abstract}

Keywords: demand analysis, econometric modeling, pest control, termite control, urban pest

\section{INTRODUCTION}

The pest control industry is one of the main global service industries, and its market continues to grow. The worldwide market in 2017 was worth US\$18 billion and projected to be US\$ 23 billion in 2023. North America is the primary market even though Asia is believed to be the most potential emerging market with the worth of US\$2.6 billion after South America and Europe (Rentokil 2018). Meanwhile, the pest control market in Indonesia that were scattered in more than 600 companies in several cities in 2013 was estimated at US\$22.5 million, with annual growth ranging from 7-9\% (Sugiarman 2014).

The pest control industry in Indonesia is concentrated in urban cities, especially in Jakarta. At least, about 86 companies in Jakarta were officially registered in the Association of Indonesian Pest Control Companies (Asosiasi Perusahaan Pengendali Hama Indonesial ASPPHAMI) or about $20 \%$ of all registered companies in Indonesia. This number could be tripled if the unregistered companies in the association are also considered. The attractiveness of Jakarta as a center of pest control business investment is due to better infrastructure, a higher population, and easier access to the market (Rusiawan et al. 2015). In addition, Jakarta's economic growth is always higher than the national economic growth and has the highest building permits compared to other urban cities (Badan Pusat Statistik 2017a; b). However, massive development and modernization of infrastructure, including building permits in Jakarta since the 1990s, including building permits, cause an environmental problem due to a lack of good quality unsustainable and quantity of infrastructure development (Steinberg 2007). This 
unsustainable development resulted in significant economic losses by pest but increased the potential demand for pest control.

In the pest control industry, termite is known as an important species and is considered as an urban pest because of its tendency to attack the human-made structures. Globally, the economic losses by the pest were estimated at least US\$ 40 billion in 2010 (Rust and Su 2012). Rentokil (2018) stated about 19\% or US\$ 3.4 billion of the pest control market in 2017 was termite control. Meanwhile, in Indonesia, it was about $34.5 \%$ of the Indonesia pest control market in 2013 (Sugiarman 2014). Further, based on the economic assessment of termite damage in several cities in 2015, the economic loss by termite in Indonesia was estimated at Rp 8.68 trillion (Nandika et al. 2015). This suggests termite is a very important pest, and the termite control is crucial in the Indonesia pest control market.

A study on the importance of controlling termites and its potential markets became necessary for the pest control industry to capture all of the potential markets. However, previous research on termites as pests simply concentrated on three major issues, namely the control treatment (Chen et al. 2015), detection of infestation (Nanda et al. 2018; Oliver-Villanueva and Abián-Pérez 2013) and economic losses (Rust and Su 2012). Literature in termite control market is limited though very important; for instance, Bhandari (2003) and Rentokil (2018).

Concerning the potential termite control market, this research was conducted to enrich the study on the economic side of termite control, particularly a demand side of the termite control market. Since Jakarta is a center of pest control business investment, the demand for termite control in Jakarta was then studied. Determinants of termite control demand were identified, and its demand model was then developed based on companies' consumer data. The results are expected to be the consideration factors for termite control management to grow their business appropriately and may enhance knowledge related parties such as insecticides formulator companies and governments to understand the termite control market.

\section{MATERIALS AND METHODS}

\section{Determinants Selection and Data Availability}

This research is a study of the demand for termite control services in DKI Jakarta Province. Based on location selection, only companies and consumer data in DKI Jakarta Province were analyzed. Therefore, other variables used referred to the condition of Jakarta at the same time. Besides based on location, company selection refers to Governor Regulation No. 35 of 2013 and SNI concerning termite control. This regulation states that a company must have a permit and is a recognized member of the association so that the selected company is a member of the Association of Indonesian Pest Control Companies or ASPPHAMI Jakarta.

The determinants investigated were based on the previous studies (Amaro and Lima 2016; Bhandari 2003; Paudel et al. 2007; Rentokil 2018). Bhandari (2003) examined various variables to determine termite control reference models in Louisiana. This study used 31 variables in building probit and logistical models to determine willingness to pay. All variables generally describe home characteristics, knowledge of termites, and sociodemography. In addition, the effects of variations in the risk of termite infestation in each region was implicitly captured from the selected respondents. Paudel et al. (2007) based on data from Bhandari (2003), updated the model by omitting insignificant variables and changing some variables into dummy variables. This study used six dummy and three continuous variables. The dummy variables are location, type of foundation, house prices, knowledge on termites, gender, and ethnicity, whereas continuous variables are age, education, and income. Meanwhile, Rentokil (2018) stated that population growth, urbanization, the increase of the middle class, climate change, disease vectors, increasing business competition, and increased intolerance of pests are 
determinant factors affecting demand for pest control. Amaro and Lima (2016) estimated that the demand curve for pesticide use and found price, income, and consumer knowledge have a significant effect.

Based on the described determinants above and coupled with the availability of data, this study investigated the impacts of six variables on termite control demand. Termite control $(Y)$ was measured by the serviced building area (in meter square). Six variables that were perceived to affect the demand were service price of termite control, customer income, prices of substitute services, building permits, company size, and risk class of termite infestation. Only monthly customer data in the year 2017 from four companies: one large company, one medium company, and two small companies, were obtained and used in this study.

The service price of termite control was determined by dividing contract value with a serviced building area for each customer. Data on contract value and serviced building areas were obtained from the companies. The termite control service was undoubtedly affected by customer income, as suggested by microeconomic theory and studied by Bhandari (2003) and Rentokil (2018). Unfortunately, this needed customer income data were not recorded by the company. This customer income was then proxied by monthly Gross Regional Domestic Product (GRDP), which was determined by averaging the quarterly GRDP data provided by the Central Bureau of Statistics Indonesia (BPS). This Price of substitutes was proxied by the average price index for ready-to-use structural metals (steel, aluminum, and other metals) published by BPS. These structural metals are assumed to be a substitute for termite control since termite does not infest it. Building permits were proxied by the monthly number building construction permits determined by averaging the annual number of building construction permits issued by the Jakarta provincial government (Communication, Informatics and Statistics Agency, DKI Jakarta, 2018). As indicated by Bhandari (2003), the risk class of termite infestation of building location was also investigated in this study. The risk class of termite infestation in Jakarta developed by Arinana (Arinana 2017) was used.

\section{Model Specification}

Since there was no established model, the ad-hoc models were then used to identify determinants of termite control demand (Zarnikau 2003). Two models of termite control service demand were investigated, as presented in equations (1) and (2). Equation 1 showed the linear model specification with dummy variables for the demand function. Equation 2 showed the double log model specification derived from the Cobb-Douglas function (exponential) (Gujarati and Porter 2009) with a logarithm transformation, including dummy variables.

$y_{i j}=\alpha+\beta_{1} x_{1 i j}+\beta_{2} x_{2 i j}+\beta_{3} x_{3 i j}+\beta_{4} x_{4 i j}+\gamma_{i} S_{i}+\delta_{j} R_{j}+\varepsilon_{i j}$
$\ln y_{i j}=\alpha+\beta_{1} \ln x_{1 i j}+\beta_{2} \ln x_{2 i j}+\beta_{3} \ln x_{3 i j}+\beta_{4} \ln x_{4 i j}+\gamma_{i} S_{i}+\delta_{j} R_{j}+\varepsilon_{i j}$

where:

$y_{i j}=$ the treated area as the number of demands in company $i$ at month $j$,

$x_{1 i j}=$ price index of termite control services in company $i$ at month $j$,

$x_{2 j}=$ GRDP per month at month $j$,

$x_{3 j}=$ building permits at month $j$,

$x_{4 i j}=$ price index of structural metals at month $j$,

$S_{1} \quad=$ dummy variable; 1 if the company is large, 0 if aside from that,

$S_{2} \quad=$ dummy variable; 1 if the company is medium, 0 if aside from that,

$S_{3} \quad=$ dummy variable; 1 if the company is small, 0 if aside from that,

$R_{1} \quad=$ dummy variable; 1 if the risk of termite infestation is high, 0 if aside from that,

$R_{2}=$ dummy variable; 1 if the risk of termite infestation is moderate, 0 if aside from that,

$R_{3} \quad=$ dummy variable; 1 if the risk of termite infestation is low, 0 if aside from that,

$\beta, \gamma, \delta=$ parameter of the main explanatory variable; company's dummy; and risk class dummy. 
The Least Square Dummy Variables (LSDV) technique was used to estimate both models with dropping one dummy variable for each category to avoid perfect collinearity. In this study, the second dummy variable in each category was dropped to become a benchmark. The dropping makes it easy to interpret the parameters as a differentiator for each dummy variable in one category (Gober and Freeman 2005). The value of the dummy variable coefficient in this method implies the difference in demand for a variable against the benchmark in one category. For example, the demand difference between large companies and medium-sized companies is $\gamma_{1}$, whereas the demand difference between in low-risk areas with medium-risk areas is $\delta_{3}$.

\section{Specification Testing}

Several tests such as multicollinearity, autocorrelation, and heteroscedasticity tests were carried out to ensure that the model met the assumptions of the Classical Linear Regression Method (CRLM). Multicollinearity occurs when there is a linear relationship in some or all independent variables. Multicollinearity was detected by looking at the Variance Inflation Factors (VIF) value. This VIF test is one of the most common testing methods (Wooldridge 2013). If the VIF value for a variable is more than 2.5 , or the correlation is more than 0.6 , it indicates that multicollinearity has occurred (Johnston et al. 2018). However, the VIF results of dummy variables in the LSDV method might have inflated (Murray et al. 2012), but it can be ignored (O'Brien 2017). The correlation was then conducted to determine which explanatory variables are correlated. A correction was made by omitting one of the closely correlated variables (Gujarati and Porter 2009).

A heteroscedasticity test was carried out using the White test (White 1980). When heteroscedasticity was detected, the Feasible Generalized Least Square (FGLS) method proposed by Wooldridge (2013) was conducted. However, if heteroscedasticity is persistent Ordinary Least Squares (OLS) with Robust Standard Error (RSE) technique was then applied (Long and Ervin 2010; Wooldridge 2013).

Autocorrelation was detected by looking at Durbin Watson d statistics (DW value) when DW value is much lower or higher than 2. The autoregressive or AR (1) technique was then conducted to correct violations. When autocorrelation and heteroscedasticity simultaneously occurred, the Feasible Generalized Least Square (FGLS) method was then applied (Wooldridge 2013).

After all assumptions are met, the first thing that must be considered in determining the best model is the sign of the coefficient of a model, which must be in accordance with the theory. The significance of the coefficient can only be interpreted if the sign is right based on theory. If the sign and significance of coefficients in two models are as expected, then the accuracy of forecasting using the Root Mean Square Error (RMSE) criteria was used to determine the best model. The RMSE was chosen because its value is not inflated due to the effect of the dummy variable in the LSDV approach compared to R-squared (Simangunsong and Buongiorno 2001). Furthermore, the value of elasticity and interpretation of the dummy variable coefficients will be analyzed based on the best demand model.

\section{RESULTS AND DISCUSSION}

\section{Costumers' characteristics}

Generally, termite pest control can be divided into three main treatments, namely chemical liquid treatment, baiting, and mixed. About 948 new customers were recorded at four pest control companies being studied in 2017 . $79 \%$ of new customers were recorded by the large company (TRM), $10 \%$ by the medium company (LRS) and $11 \%$ by the small companies (PNT and NTN). These customers sample was in line with the termite control market where 
$60 \%$ of the market share only held by 8 large pest control companies. About $46 \%$ of total new customers prefer baiting rather than chemical liquid treatment (Figure 1). The reason is that baiting application is easier and the risk of damage caused by drilling and chemical waste is lower than chemical liquid treatment. In contrast, companies in the United States of America do chemical treatment more often than baiting treatment (Rust and $\mathrm{Su} 2012$ ).

Refer to the category of housing group in Indonesia (Suparno and Marlina 2006), 75\% of customers building were categorized as luxury homes $\left(>120 \mathrm{~m}^{2}\right), 25 \%$ of customers as medium $\left(36-120 \mathrm{~m}^{2}\right)$ and there are no customers with simple homes $\left(<36 \mathrm{~m}^{2}\right)$. These findings indicated that the termite control market was mostly for customers with luxury and medium homes or upper- and middle-class economies. This is expected due to the price for termite control is quite expensive for families with lower middle income. The average termite control price of 31,000 rupiah per cubic meter depends on the area and treatment to be carried out. Figure 1 also shows small companies only focused on one specific control technique. As shown in Figure 1 PNT only did baiting, while NTN only did a liquid treatment.

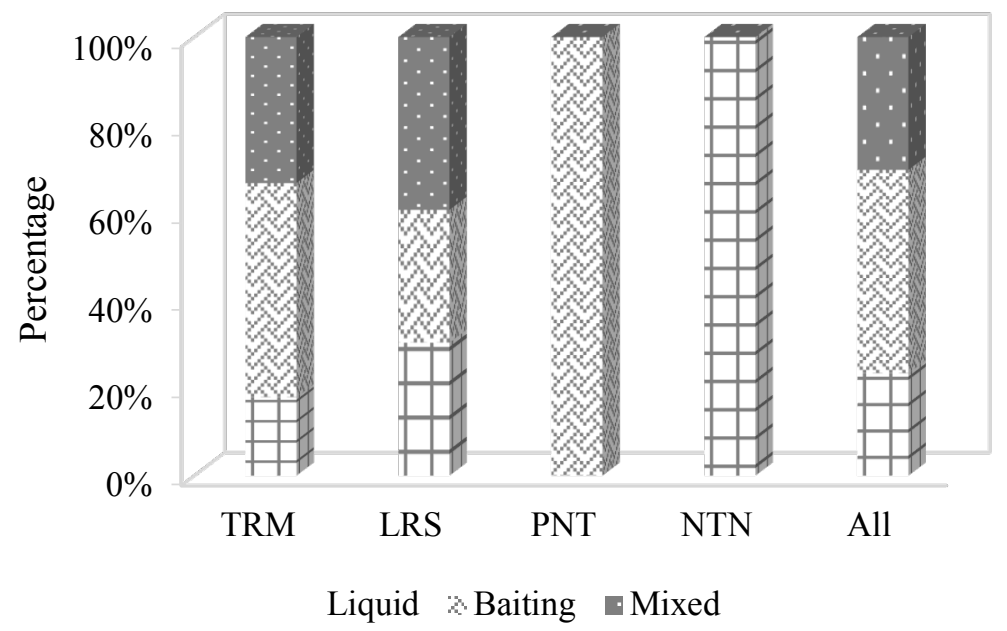

Figure 1. Selection of termite control treatment in each firm.

With regard to the termite risk area classes (Arinana 2017), 59\% of customers were located at a low-risk area, $25 \%$ of customers at a medium-risk area, and $16 \%$ of customers at a high-risk area. This distribution indicated that customers were not centered on the highest risk class.

\section{Estimation Results and Elasticity}

All stages of the testing results of the regression and linear model can be seen in Table 1. The initial OLS method has a high R-squared value but some variables are not significant, this indicates the occurrence of multicollinearity. VIF testing was then performed and it was found that the VIF value for the GRDP variable was 2.62. This value indicates the multicollinearity between GRDP and other variables. Correlation analysis was then carried out and showed a fairly high correlation between GRDP and building permits $(>65 \%)$. So it can be concluded that the GRDP variable is omitted in subsequent regressions to avoid correlation with other variables. The decision to eliminate this variable is made to avoid invalid coefficients because it has large standard errors resulting from the violation. The decision was also based on the Redundant Variable Test which showed that the GRDP variable was insignificant and would not result in specification errors due to removing the variable that should have been analyzed (omitted variable).

The assumption of autocorrelation in OLS regression has been fulfilled based on the DW value, which is equal to 2.21 . This value is still within the confidence interval, so the null 
hypothesis which says that autocorrelation occurred can be rejected. On the other assumption, based on the White test, the error is heteroscedastic, so FGLS needs to be done to correct it. The regression results FGLS apparently not able to fix heteroscedasticity based test White test. The linear model then uses the OLS technique with RSE and the results are shown in Table 2. Based on the estimation results in the linear model, only the price of termite and dummy control services for large companies has an appropriate expected sign and significant at a $5 \%$ confidence level.

The regression results in the double log model in Table 1 showed the same indication as the linear model for multicollinearity testing, the GRDP variable in the double log model must be omitted from the equation to avoid multicollinearity. The results of White test testing showed that there was no heteroscedasticity. However, the DW value indicates that the assumption of autocorrelation has been violated. To correct these violations, the AR (1) and FGLS autoregressive methods were performed. The results of the FGLS showed that the regression can correct autocorrelation violation but cause heteroscedasticity. Whereas the AR (1) method can correct autocorrelation violation. The results of parameter estimation after correction in the double log model are shown in Table 2 .

After both models have been corrected, it can be concluded that the double log model is better than the linear model. This can be seen from the variable of price of termite control service and the dummy for large companies, and building permits have appropriate expectation sign in accordance with the theory and significant at a 5\% confidence level. Although the linear model has slightly better values of RMSE and adjusted $\mathrm{R}^{2}$, the double log model showed a lower variance, this is indicated by the significance of the variable and standard error.

Based on the double log model, the demand for termite control was found to be elastic as indicated by the parameter of the termite control prices variable of -1.098 . This price elasticity of demand means demand for termite control would decrease (increase) by $1.098 \%$ if the termite control prices increase (decrease) by 1\%. This elastic demand encouraged companies to reduce their service price to increase their total income as seen by the tendency of companies to reduce prices over time in 2017. Further, the service was elastic due to the percentage of costs for controlling termites over income is relatively large. However, making decisions for termite control is not urgent, so that customers still have time to look for suitable substitutions. This results in elasticity not so high.

Based on the parameter values of the building permits variable, it is proven to have a significant influence on service demand. These findings suggest that companies prioritize market expansion to areas with high building growth. Besides that, it can also be suggested to prioritize the market with upper middle-class economy class with houses classified as luxury and middle-class.

Cross elasticity of termite control demand has a positive sign as expected because structural metals are considered as substitutes for termite control. This is indicated by the parameter of structural metal prices valued at +5.315 . However, this parameter is not significant at the $5 \%$ confidence level. Based on the adjusted R-squared value with a value of 0.850 indicates that the model can explain variations of termite control well by $85 \%$. 
Table 1. Regression process for linear and double log models.

\begin{tabular}{|c|c|c|c|c|c|c|c|c|c|c|c|}
\hline \multirow{2}{*}{ Model } & \multirow{2}{*}{$\begin{array}{c}\text { Method / } \\
\text { Test }\end{array}$} & \multirow{2}{*}{ Value } & \multicolumn{9}{|c|}{ Variable } \\
\hline & & & c & $\mathbf{x}_{1}$ & $\mathbf{x}_{2}$ & $\mathbf{x}_{3}$ & $\mathbf{X}_{4}$ & $\mathbf{S}_{1}$ & $\mathbf{S}_{3}$ & $\mathbf{R}_{1}$ & $\mathbf{R}_{3}$ \\
\hline LSDV & OLS & & $-12843,650$ & $-151,666$ & $2.42 \mathrm{E}-07$ & 12,626 & 258,448 & 13624,720 & 43,240 & $-574,846$ & $-335,448$ \\
\hline \multirow[t]{11}{*}{ Linier } & VIF & & NA & 2,29 & 2,62 & 2,24 & 1,17 & & & & \\
\hline & White-test & $\mathbf{F}=\mathbf{0 , 0 0 3}$ & & & & & & & & & \\
\hline & DW & 2,207 & & & & & & & & & \\
\hline & Adj. $\mathrm{R}^{2}$ & 0,890 & & & & & & & & & \\
\hline & FGLS & & $-8.855,907$ & $-240,834$ & & 30,861 & 278,025 & $11.091,180$ & $1.004,173$ & $-1.290,415$ & $-1.353,483$ \\
\hline & White-test & $\mathbf{F}=\mathbf{0 , 0 0 0}$ & & & & & & & & & \\
\hline & DW & 2,062 & & & & & & & & & \\
\hline & Adj. $\mathrm{R}^{2}$ & 0,822 & & & & & & & & & \\
\hline & OLS RSE (HC3) & & $-13333,380$ & $-151,376$ & & 14,545 & 268,191 & 13698,520 & 43,050 & $-699,561$ & $-294,836$ \\
\hline & DW & 2,224 & & & & & & & & & \\
\hline & Adj. $\mathrm{R}^{2}$ & 0,892 & & & & & & & & & \\
\hline LSDV & OLS & & $-9,308$ & $-0,793$ & $-0,867$ & 1,723 & 6,645 & 1,781 & $-0,471$ & $-1,081$ & $-0,232$ \\
\hline \multirow[t]{14}{*}{ Double Log } & DW & 1,620 & & & & & & & & & \\
\hline & Adj. $\mathrm{R}^{2}$ & 0,890 & & & & & & & & & \\
\hline & OLS & & $-22,464$ & $-0,817$ & & 1,444 & 5,702 & 1,707 & $-0,468$ & $-0,980$ & -0.277564 \\
\hline & White-test & $\mathrm{F}=0,087$ & & & & & & & & & \\
\hline & DW & 1,587 & & & & & & & & & \\
\hline & Adj. $R^{2}$ & 0,845 & & & & & & & & & \\
\hline & FGLS & & 5,721 & $-3,897$ & & 1,754 & 2,272 & $-0,316$ & $-0,128$ & $-0,959$ & $-0,228$ \\
\hline & White-test & $\mathbf{F}=\mathbf{0 , 0 0 0}$ & & & & & & & & & \\
\hline & DW & $\mathbf{1 , 5 9 7}$ & & & & & & & & & \\
\hline & Adj. $\mathrm{R}^{2}$ & 0,731 & & & & & & & & & \\
\hline & $\operatorname{AR}(1)$ & & $-20,011$ & $-1,098$ & & 1,566 & 5,316 & 1,638 & $-0,398$ & $-1,013$ & $-0,363$ \\
\hline & White-test & $\mathrm{F}=0,303$ & & & & & & & & & \\
\hline & DW & 2,161 & & & & & & & & & \\
\hline & Adj. $\mathrm{R}^{2}$ & 0,85 & & & & & & & & & \\
\hline
\end{tabular}


Table 2. Parameter estimates of the linear and double log models of termite control demand.

\begin{tabular}{|c|c|c|c|c|}
\hline \multirow{3}{*}{ Variables } & \multicolumn{4}{|c|}{ Regression models } \\
\hline & \multicolumn{2}{|c|}{ Linear } & \multicolumn{2}{|c|}{ Double log } \\
\hline & Parameters & P-value & Parameters & P-value \\
\hline Constant & -13333.380 & 0.430 & -20.011 & 0.194 \\
\hline Price of termite control services & & & & \\
\hline$\left(\mathrm{x}_{1}\right)$ & -151.375 & 0.000 & -1.098 & 0.013 \\
\hline Building permits $\left(\mathrm{x}_{3}\right)$ & 14.545 & 0.079 & 1.566 & 0.000 \\
\hline Price of structural metals $\left(\mathrm{x}_{4}\right)$ & 268.191 & 0.097 & 5.315 & 0.095 \\
\hline \multicolumn{5}{|l|}{ Dummy for company size } \\
\hline $\mathrm{S}_{1}$ & 13698.520 & 0.000 & 1.638 & 0.000 \\
\hline $\mathrm{S}_{2}$ & 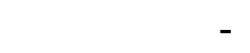 & & - & \\
\hline $\mathrm{S}_{3}$ & 43.050 & 0.957 & -0.398 & 0.126 \\
\hline \multicolumn{5}{|l|}{ Dummy for risk class } \\
\hline $\mathrm{R}_{1}$ & -699.523 & 0.529 & -1.872 & 0.069 \\
\hline $\mathrm{R}_{2}$ & - & & - & \\
\hline $\mathrm{R}_{3}$ & -294.836 & 0.637 & -2.015 & 0.051 \\
\hline \multicolumn{5}{|l|}{ Statistics } \\
\hline Durbin-Watson stat. & 2.224 & & 2.161 & \\
\hline F-Statistic & 56.852 & & 34.33 & \\
\hline RMSE & 2842.049 & & 3478.432 & \\
\hline Adjusted R-squared & 0.893 & & 0.850 & \\
\hline Number of observations & 48 & & 48 & \\
\hline
\end{tabular}

\section{Dummy Variable Interpretation}

The estimation results show that the risk class does not affect demand as indicated by the insignificance of all dummy variables for the risk class at a 5\% confidence level. This finding was slightly different from the general assumption that a region with a higher risk will encourage consumers to consider controlling termites. Possible reasons why this phenomenon can occur are: 1) differences in awareness for termite infestation among customers; 2) around $59 \%$ of customers come from areas with low risk; and 3) differences in the tolerance threshold are influenced by variables that cannot be explained in this study. Some variables that are thought to explain the differences include education, ethnicity and building specifications. Although the risk does not affect demand, risk mapping can be used for risk analysis for consideration of the provisions of company guarantees. Differentiation of the warranty needs to be done considering that until now all companies provide the same guarantee for all types of risks.

The dummy variable of company size shows the influence on termite control demand. Demand for large companies was greater than small and medium-sized companies. While small and medium-sized companies do not have significantly different demands. This can be seen from the insignificance of the coefficient of small companies.

\section{CONCLUSIONS}

The double log model with the variables of the price of termite control services, building permits, structural metal prices, company size, and termite risk class can be used to explain the demand for termite control. The double log model was the best model based on the consideration that the model has fulfilled the Classical Linear Regression Model (CLRM) 
assumptions with expected sign and significance in accordance with the theory. Also, the adjusted R-squared value is quite high (0.85) to explain variations in termite control demand. Based on the parameters of the double log model, it can be concluded that the price elasticity was elastic $(-1,098)$. Studies on differences in awareness of termite infestation and differences in tolerance thresholds that are thought to affect termite control preferences can be carried out to enrich the study in this demand. In addition, an analysis of the influence of building characteristics, education, gender, age, ethnicity, home values and knowledge about termite infestation on termite control demand can be analysed.

\section{ACKNOWLEDGMENTS}

Authors thanks to Association of Indonesian Pest Control Companies (Asosiasi Perusahaan Pengendalian Hama Indonesia/ASPHAMMI) Jakarta for supporting this research.

\section{REFERENCES}

Amaro, C., and Lima, J. 2016. Estimating the Demand Curve for Sustainable Use of Pesticides from Contingent-Valuation Data. Ecological Economics Elsevier B.V. 127: 121-128. DOI: $10.1016 /$ j.ecolecon.2016.04.019

Arinana. 2017. Prediction Model Development of Subterranean Termite Hazard Risk Class in DKI Jakarta Province Based on the Species Composition, Soil and Climate Characteristics. IPB University.

Badan Pusat Statistik. 2017a. Konstruksi dalam Angka 2017. Jakarta.

Badan Pusat Statistik. 2017b. Provinsi DKI Jakarta dalam Angka 2017. Jakarta.

Bhandari, D. 2003. An Economic Analysis of Homeowners's Preferences and Perceptions Regarding Termite Prevention and Control in Lousiana. Louisiana State University and Agricultural and Mechanical College.

Chen, Z., Qu, Y., Xiao, D., Song, L., Zhang, S., Gao, X., Desneux, N., and Song, D. 2015. Lethal and Social-Mediated Effects of Ten Insecticides on the Subterranean Termite Reticulitermes speratus. Journal of Pest Science 88(4): 741-751. DOI: 10.1007/s10340015-0656-0

Evans, T. A. 2002. Assessing efficacy of Termatrac???; A new microwave based technology for non-destructive detection of termites (Isoptera). Sociobiology 40(3): 575-583. DOI: $10.1167 / 2.7 .86$

Gober, R. W., and Freeman, G. L. 2005. Interpretation of Shifted Binary Interpretive Framework Coefficients Using a Classical Regression Problem. Journal of Management Information and Decision Sciences 8: 115-123.

Gujarati, D. N., and Porter, D. C. 2009. Basic Econometrics. McGraw-Hill/Irwin, Boston.

Johnston, R., Jones, K., and Manley, D. 2018. Confounding and Collinearity in Regression Analysis: A Cautionary Tale and an Alternative Procedure, Illustrated by Studies of British Voting Behaviour. Quality \& Quantity 52(4): 1957-1976. DOI: 10.1007/s11135-0170584-6

Long, J. S., and Ervin, L. H. 2010. Using Heteroscedasticity Consistent Standard Errors in the Linear Regression Model. The American Statistician 54(3): 217-224. DOI: 10.1080/00031305.2000.10474549

Murray, L., Nguyen, H., Lee, Y. F., Remmenga, M. D., and Smith, D. W. 2012. Variance Inflation Factors in Regression Models with Dummy Variables. in: 24th Annual Conference on Applied Statistics in Agriculture 1-18. 
Nanda, M. A., Seminar, K. B., Nandika, D., and Maddu, A. 2018. Discriminant Analysis as a Tool for Detecting the Acoustic Signals of Termites Coptotermes Curvignathus (Isoptera: Rhinotermitidae). International Journal of Technology 4: 840-851. DOI: 10.14716/ijtech.v9i4.455

Nandika, D., Rismayadi, Y., and Diba, F. 2015. Rayap: Biologi dan Pengendaliannya. Universitas Muhamadiyah, Surakarta.

O’Brien, R. M. 2017. Dropping Highly Collinear Variables from a Model: Why it Typically is Not a Good Idea. Social Science Quarterly. DOI: 10.1111/ssqu.12273

Oliver-Villanueva, J. V., and Abián-Pérez, M. A. 2013. Advanced Wireless Sensors for Termite Detection in Wood Constructions. Wood Science and Technology 47(2): 269-280. DOI: 10.1007/s00226-012-0485-8

Paudel, K. P., Dunn, M. A., Bhandari, D., Vlosky, R. P., and Guidry, K. M. 2007. Alternative Methods to Analyze the Rank Ordered Data: A Case of Invasive Species Control. Natural Resource Modeling 20(3): 451-471. DOI: 10.1111/j.1939-7445.2007.tb00216.x

Pindyck, R. S., and Rubinfeld, D. L. 1998. Econometric models and economic forecasts. Mcgraw-Hill College.

Rentokil. 2018. The Rentokil Pest Control Report 2018: Insight from Pest Control Markets Across the Globe. London.

Rusiawan, W., Tjiptoherijanto, P., Suganda, E., and Darmajanti, L. 2015. System Dynamics Modeling for Urban Economic Growth and CO2 Emission: A Case Study of Jakarta, Indonesia. Procedia Environmental Sciences. DOI: 10.1016/j.proenv.2015.07.042

Rust, M. K., and Su, N. 2012. Managing Social Insects of Urban Importance. Annual Review of Entomology 57: 355-375. DOI: 10.1146/annurev-ento-120710-100634

Simangunsong, B. C. H., and Buongiorno, J. 2001. International Demand Equations for Forest Products: A Comparison of Methods. Scandinavian Journal of Forest Research 16(2): 155-172. DOI: $10.1080 / 028275801300088242$

Steinberg, F. 2007. Jakarta: Environmental Problems and Sustainability. Habitat International 31(3-4): 354-365. DOI: 10.1016/j.habitatint.2007.06.002

Sugiarman. 2014. Analisis Pengaruh Kualitas Produk dan Layanan Pelanggan Terhadap Kepuasan dalam Membentuk Loyalitas Pest Control Operator pada PT Bayer Indonesia. Sekolah Pascasarjana Institut Pertanian Bogor.

Suparno, S. M., and Marlina, E. 2006. Perencanaan dan Pengembangan Perumahan. Penerbit Andi, Yogyakarta.

White, H. 1980. A Heteroskedasticity-Consistent Covariance Matrix Estimator and a Direct Test for Heteroskedasticity. Econometrica. DOI: 10.2307/1912934

Wooldridge, M. 2013. Introductory Econometrics. Cengage Learning. DOI: 10.1016/j.jconhyd.2010.08.009

Zarnikau, J. 2003. Functional Forms in Energy Demand Modeling. Energy Economics 25(6): 603-613. DOI: 10.1016/S0140-9883(03)00043-4 